\title{
SEISMIC ASSESSMENT AND STRENGTHENING INTERVENTIONS OF ATOP SINGLE-BLOCK ROCKING ELEMENTS IN MONUMENTAL BUILDINGS: THE CASE STUDY OF THE SAN FELICE SUL PANARO FORTRESS
}

\author{
S. DEGLI ABBATI ${ }^{1 *}$, S. CATTARI ${ }^{2}$, S. LAGOMARSINO ${ }^{2}$ AND D. OTTONELLI $^{2}$ \\ ${ }^{1}$ Department of Civil, Chemical and Environmental Engineering \\ University of Genova \\ Via Montallegro 1, 16145 Genova, Italy \\ e-mail: stefania.degliabbati@unige.it (*corresponding author) \\ ${ }^{2}$ Department of Civil, Chemical and Environmental Engineering \\ University of Genova \\ Via Montallegro 1, 16145 Genova, Italy \\ email: \{serena.cattari, sergio.lagomarsino,daria.ottonelli\}@unige.it
}

Keywords: Masonry, Merlons, Kinematic analyses, Macro-block models

\begin{abstract}
The paper describes the seismic assessment of the San Felice sul Panaro Fortress (Italy), focusing the attention on the activation of the out-of-plane response of the North walkway, characterized by the presence of an apparatus of merlons which highlighted a significant damage after the Emilia earthquake (2012). Nonlinear kinematic analyses have been performed, referring to a macro-block model and considering both the original configuration and two different possible strengthened strategies. For the definition of the seismic input in terms of floor spectra, the analyses also benefitted from the results obtained for the global response through a detailed $3 D$ model of the whole fortress. The results were coherent with the observed damage after the seismic event, highlighting in this way the reliability of the adopted modelling strategies and analysis method, and allowed to outline possible strengthening solutions targeted to minimize the impact on the monument and guarantee its preservation.
\end{abstract}

\section{INTRODUCTION}

The seismic assessment and the protection of historical fortified buildings represent a very challenging issue: firstly, because of their significant vulnerability, as testified by past seismic events ([1], [2]); and secondly, due to the necessity to combine the need of safety with the conservation aims. In particular, their complex configurations make them particularly susceptible to the activation of local mechanisms, involving the out-of-plane response of singular walls or protruding elements (called merlons), that are the solid standing part of battlements or crenelated parapets, typical of these kinds of structures. The collection and cataloguing of seismic damages on fortified architectures ([1],[2]) highlighted that merlons are frequently damaged, even for quite low accelerations. 
Within this context, the paper illustrates the results obtained from nonlinear analyses performed on the San Felice sul Panaro Fortress (Italy), focusing the attention only on the activation of the out-of-plane response of the North masonry walkway, that is characterized by the presence of an apparatus of merlons placed at its top, which resulted significantly hit by the Emilian earthquake (2012).

In particular, nonlinear kinematic analyses have been performed referring to a MacroBlock Model (MBM). For the definition of the seismic input, and in particular for the computation of the floor spectra, the analyses also benefitted from the results obtained for the global response through a detailed 3D model of the whole fortress, as already illustrated in [3]. Both the original configuration and some possible strengthened states have been analysed in order to: firstly, validate the modelling strategy and the method of analysis adopted through the comparison with the observed damage; secondly, verify the effectiveness of possible mitigation strategies.

\section{CASE-STUDY DESCRIPTION: THE SAN FELICE SUL PANARO FORTRESS}

The San Felice sul Panaro Fortress ([4],[5]) is a medieval historical building dating back to the $14^{\text {th }}-15^{\text {th }}$ century and located near the city of Modena in San Felice sul Panaro (Italy). This fortress represents a typical example of Emilian fortified medieval architecture, composed by a very massive main structure, characterized by a compact quadrilateral plan with an inner yard and five towers: four of them are localized at the corners, while the other one is placed

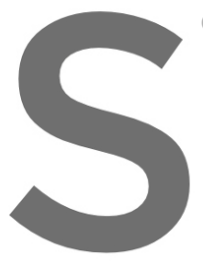
on the north fortress
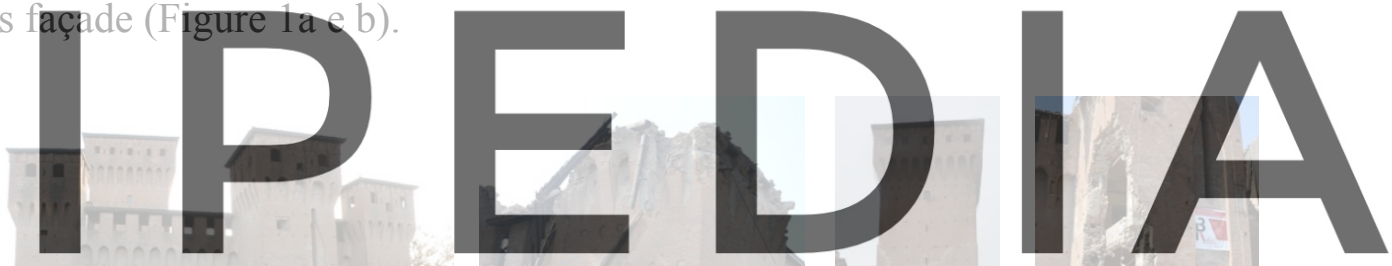

Register for free at https//www.scipedia.com to download the version without the watermark a. b. d. e.

Figure 1: Schematic floor plan (a) and general view (b); examples of collapse mechanisms exhibited by the fortress: collapse of a minor tower's roof (c), damage pattern in the Mastio (d) and collapse in the north tower (e)

The fortress was seriously damaged by the Emilian earthquake of May 2012 [1], which induced: the collapse of the four minor towers roofs (Figure 1c); shear cracks on the main body of the Mastio (Figure 1d) and of the other towers; and extensive collapse in the north tower (Figure 1e), also promoted by some heavy interventions realized in the past [1]. Furthermore, a significant damage was concentrated in the merlons that exhibited different failure mechanisms and different levels of damage, as a function of their position on the fortress. In particular, some of them exhibited horizontal cracks at their base, others shear cracks, while most of them were interested by an out-of-plane mechanism which even induced in some cases the overturning of some elements. Figure 2 shows some pictures of the occurred damage, mainly concentrated in the North walkway connecting two towers (identified in Figure 2a). 


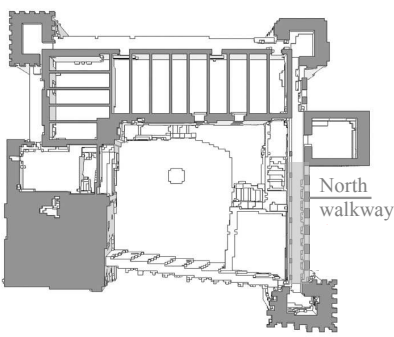

a.

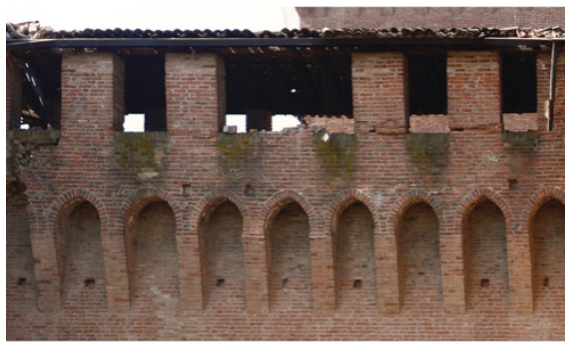

b.

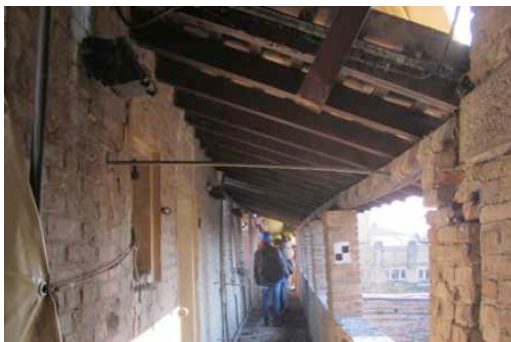

c.

Figure 2: Damage pattern after the Emilian earthquake (2012) in the apparatus of merlons

\section{SEISMIC OUT-OF-PLANE ASSESSMENT OF MERLONS}

\subsection{Adopted procedure}

Non-linear kinematic analyses have been performed, by adopting a Macro-Block Model (MBM) and using the software MB-Perpetuate, developed in the framework of the Perpetuate Project [6]. The criteria adopted for the seismic out-of-plane assessment of the San Felice sul Panaro Fortress are defined on the basis of the analyses illustrated in [7] and [8], regarding the evaluation of the capacity curve, the definition of the assumed Limit States (LSs) and the criteria adopted to provide the comparison with the seismic input. Regarding the first aspect, Figure 3 a shows the system capacity curve on which progressing Damage Levels (DLs) are identified. These latter are then corretated to corresponding L
the curve is different from the ideal one of the rigid block, in characterized by a bi-linear trend, more goherent with the one and characterized by a first elastic braneh defin

The seismic assessment has been performed, considering the between DLs and LSS:

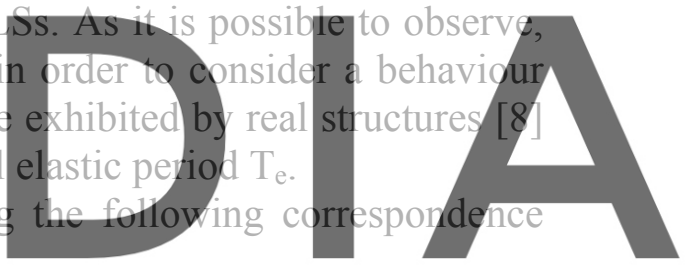

DL2 assimilated to the Damage Limit State (SLD), corresponding to the mechanism Register for freesatvattops//www.scipedia.com to download the version without the watermark

DL4 assimilated to the Safeguard Life Limit State (SLV), corresponding to the displacement $\mathrm{d}_{\mathrm{SLV}}=0.4 \mathrm{~d}_{0}$, where $\mathrm{d}_{0}$ is the value corresponding to the load multiplier $\alpha=0$ (representative - under static condition - to the collapse for overturning).

Once defined the capacity curve and the LSs of the system, the capacity curve has been compared with the spectrum in order to complete the seismic assessment (Figure 3b). In particular, in the case of local mechanisms involving macroelements placed in the upper part of the building, it has to be considered a proper modified response spectrum (floor spectrum) aimed to take into account the filtering effect provided by the main structure. For the latter, in this paper, the analytical expression recently proposed in [9] has been used, which allows evaluating the floor spectra in different points of the building and at different levels by considering the contribution of the more relevant modes, properly combined. It gives the acceleration floor spectra at the level $\mathrm{Z}$ of the main structure (where the element to be verified of period $\mathrm{T}$ and damping $\xi$ is placed) as:

$$
S_{a Z}(T, \xi)=\sqrt{\sum_{k=1}^{N} S_{a Z, k}^{2}(T, \xi)} \quad\left(\geq S_{a}(T) \eta(\xi) \quad \text { for } T>T_{1}\right)
$$


where: $S_{a}(T)$ is the acceleration response spectrum of the ground motion; $N$ is the number of considered modes, selected since they activate the out-of-plane response of the examined element; $\mathrm{S}_{\mathrm{aZ}, \mathrm{k}}(\mathrm{T}, \mathrm{z})$ is the contribution of mode $\mathrm{k}^{\text {th }}$ that is given by:

$$
S_{a Z, k}(T, \xi)= \begin{cases}\frac{A M P_{k} P F A_{Z, k}}{1+\left[A M P_{k}-1\right]\left(1-\frac{T}{T_{k}}\right)^{1.6}} & T \leq T_{k} \\ \frac{A M P_{k} P F A_{Z, k}}{1+\left[A M P_{k}-1\right]\left(\frac{T}{T_{k}}-1\right)^{1.2}} & T>T_{k}\end{cases}
$$

where:

- PFA $A_{Z, k}$ is $k^{\text {th }}$ Peak Floor Acceleration that depends on the modal parameters of the main structure in terms of natural periods $\left(\mathrm{T}_{\mathrm{k}}\right)$, modal participation coefficients $\left(\gamma_{\mathrm{k}}\right)$ and modal shapes $\left(\psi_{\mathrm{k}}(\mathrm{x}\right.$ y $\left.\mathrm{z})\right)$ and its viscous damping $\xi_{\mathrm{k}}$. Furthermore, it depends on the ground spectrum $\mathrm{S}_{\mathrm{a}}\left(\mathrm{T}_{\mathrm{k}}\right)$ calculated in correspondence of the structure natural period $T_{k}$ and properly reduced through the damping correction factor $\eta\left(\xi_{k}\right)$ (which can be calculated for example as proposed in [10]):
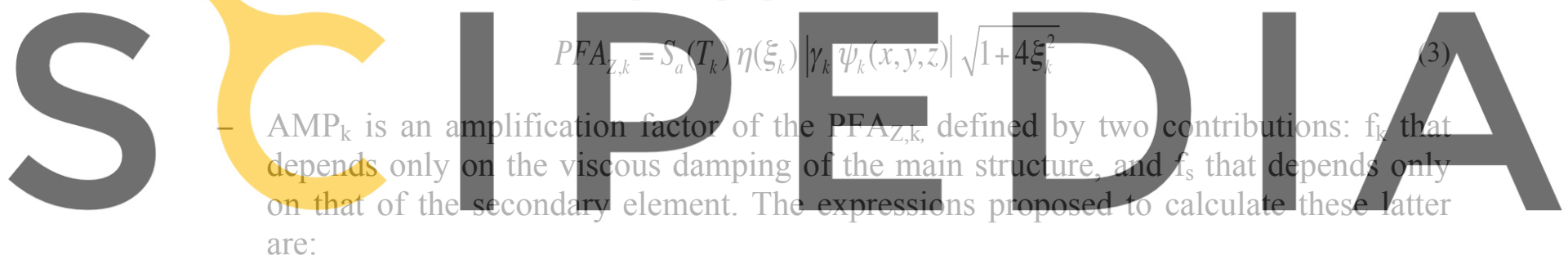
are:

Register for free at https//www.scipedia.com to dawnload the version without the watermark

$$
f_{s}=\eta(\xi)=\sqrt{\frac{0.1}{0.05+\xi}} \geq 0.55
$$

In the examined case, the floor spectra have been determined taking into account the contributions of the modes selected since considered relevant for the out-of-plane response of the merlons. The definition of such dynamic parameters takes advantage of the results of the modal analysis performed on a 3D Finite Element (FE) model of the entire structure (§3.3). Moreover, the definition of the damping value $\xi_{k}$ has been obtained by the non-linear analyses previously performed on this global model that allowed taking into account the interactions between the different towers (as already illustrated in [3]).

The final step of the procedure was the comparison between the bi-linear capacity curve and the floor spectrum. According to [7], this latter has been made smooth in order to remove all the indentations (see the dotted graph in Figure 3b), thus implicitly taking into account the peaks present in the response spectra, which could affect the dynamic response of rocking systems. From this comparison, it was possible to evaluate the values of the maximum peak 
ground accelerations (selected as the Intensity Measure -IM- aimed to describe the seismic demand) compatible with the achievement of the above-defined LSs.

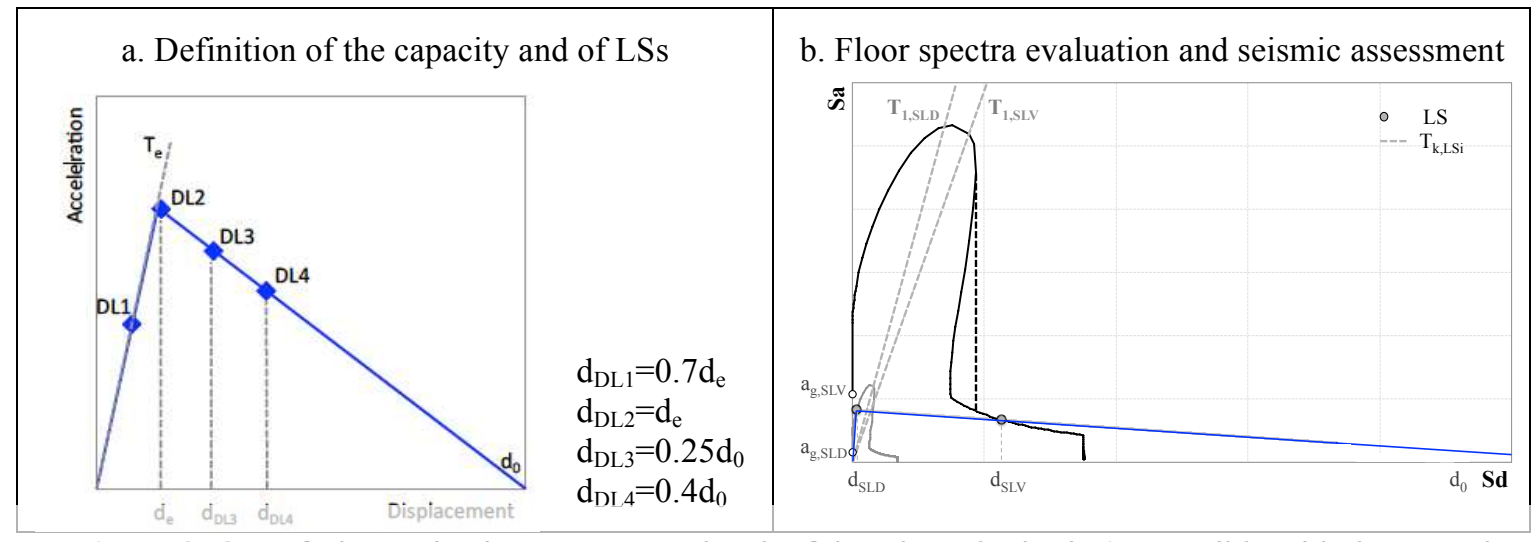

Figure 3: Out-of-plane seismic assessment: sketch of the adopted criteria (compatible with the procedure outlined in [7])

\subsection{Considered MBM models}

The analysis of the damage pattern occurred in the North walkway after the Emilian earthquake (2012) mainly highlighted the activation of two kinds of mechanisms: the rocking
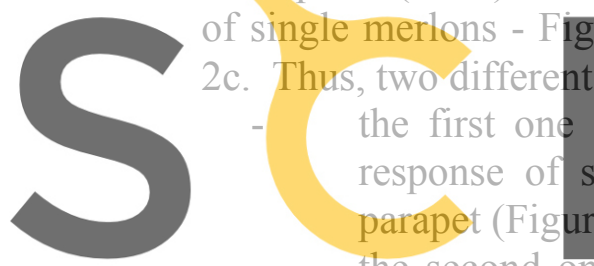

2c. Thus, two different

the first one (name

response of single

parapet (Figure 4b);

the second one (named hereafter
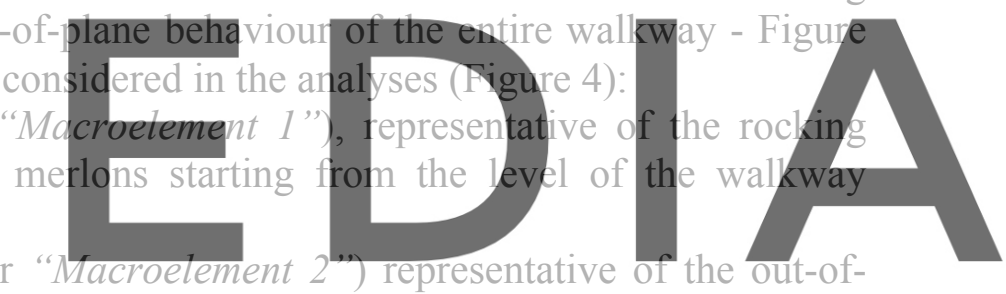

plane behaviour of the entire walkway and then characterized by the presence of two

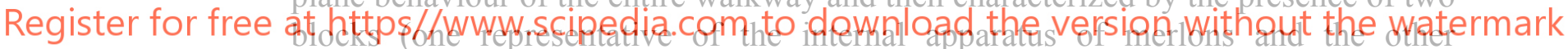

representative of the external one) connected through a timber beam of the roof

(Figure 4c). It is localized in biue in the pian presented in Figure 4a.

Figure 4 illustrates the two models considered in the analyses (the hinges are identified in yellow). For both of them, the roof has been modelled as an external force $P_{C}$, resulting from the performed loads analysis, while $W_{M}$ is the gravity load of each masonry elements (calculated as the product between the volume of each block and the masonry density equal to $18 \mathrm{kN} / \mathrm{m}^{3}$, representative of a masonry built with bricks and lime mortar).

Concerning the "Macroelement 1", two different merlons have been considered (n.1 and $\mathrm{n} .2$ in Figure 4a). This choice is due to the occurred damage, which highlighted a different damage pattern as function of the merlons position in plan along the walkway. In fact, while the central merlon (n.1 in Figure 4a) collapsed, the merlons close to the walkway extremity (n.2) did not overturn even if completely cut at the base (Figure 2b). This is coherent with the flexural behaviour exhibited by the North walkway, as highlighted by the analysis of the modal shapes on the 3D model of the entire fortress (see $\S 3.3$, Figure 5a) and it is probably due also to a different punctual effectiveness of the roof connection, which in some cases prevented the incipient overturning of merlons. 
a) North walkway plan

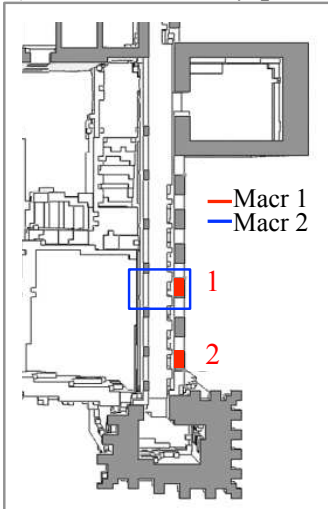

b) Macroelement 1

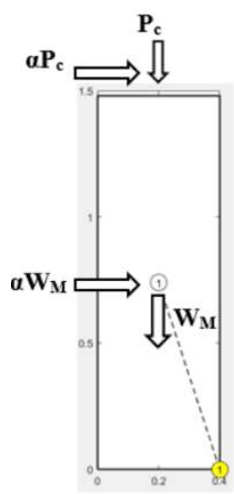

c) Macroelement 2

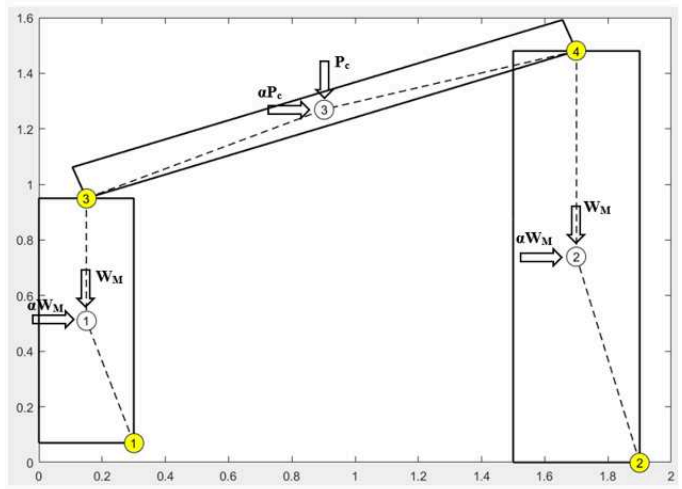

Figure 4: Macroelements considered in the analyses

\subsection{Floor spectra definition}

The San Felice sul Panaro Fortress is a complex monumental building, characterized by different interaeting units and flexible diaphragms; thus, it is characterized by many relevant modes, which can be also close one each other and characterized by modal participation coefficients which can be low, since they involve the response of limited parts of the entire structure. This feature highlights the importance of the higher modes. For this reason, in order to calculate the dynarni to perform a modal an University of Bologna called CLOUD2FEM ( modes - i.e. those activating the out-of-plane

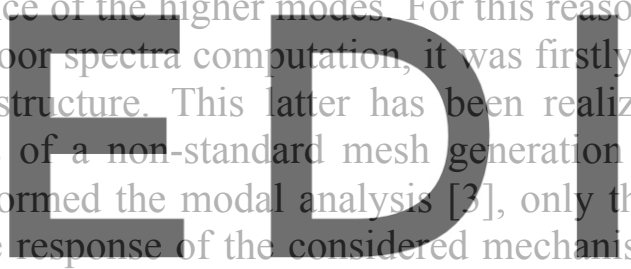
necessary
zed by the
procedure
he releyant
isms - have been selected. Among them, in order to understand the ones characterized by a more

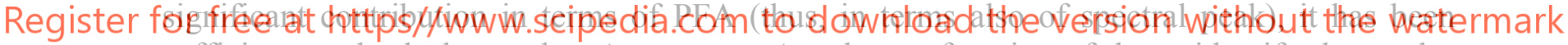
sufficient to check the product $\left|\gamma_{k} \psi_{k}(x, y, z)\right|$ and, as a function of them, identify the modes

that can be significant for the localization of the considered merions. Figure 5 a shows the deformed shapes in plan of some modes that interested the out-of-plane response of the examined mechanisms and with the most significant contribution. Figure 5b illustrates (for sake of example for the SLV LS) the comparison between: the floor spectrum evaluated for the "Macroelement 1 "(merlon n.1) and "Macroelement 2" (black curve), respectively; the one evaluated for the "Macroelement 1" (merlon n.2). They have been obtained combining the contribution of the more significant modes through the SRSS modal combination.

Furthermore, it has to be specified that they have been calculated assuming a damping for the main structure equal to $\xi_{k}=15 \%$, consistently with the post-earthquake damage pattern which highlighted as the fortress was fully in a nonlinear phase. Concerning the damping of the merlons apparatus, it has been assumed equal to $\xi=5 \%$. The input response spectrum has been defined consistently with what prescribed by NTC 2018 [13] for the site of San Felice sul Panaro. As one can see from Figure 5b, as function of the mechanisms position along the fortress walkway and of its dynamic response (Figure 5a): the floor spectrum of "Macroelement 1" (merlon n.1) is the same of "Macroelement 2", since the position of these 
latter coincides (see Figure 2a); the floor spectrum of "Macroelement 1" (merlon n.1) is higher than the one of "Macroelement 1" (merlon n.2). This is due to the fact that, while the first one is placed in the central part of the walkway (where there is the maximum deformed shape of the different modes), the second one, placed at the edges, can benefit of the restraint action guaranteed by the perimeter walls of the tower. This result is also coherent with the observed damage after the Emilian earthquake (2012) as already described (Figure 2b).

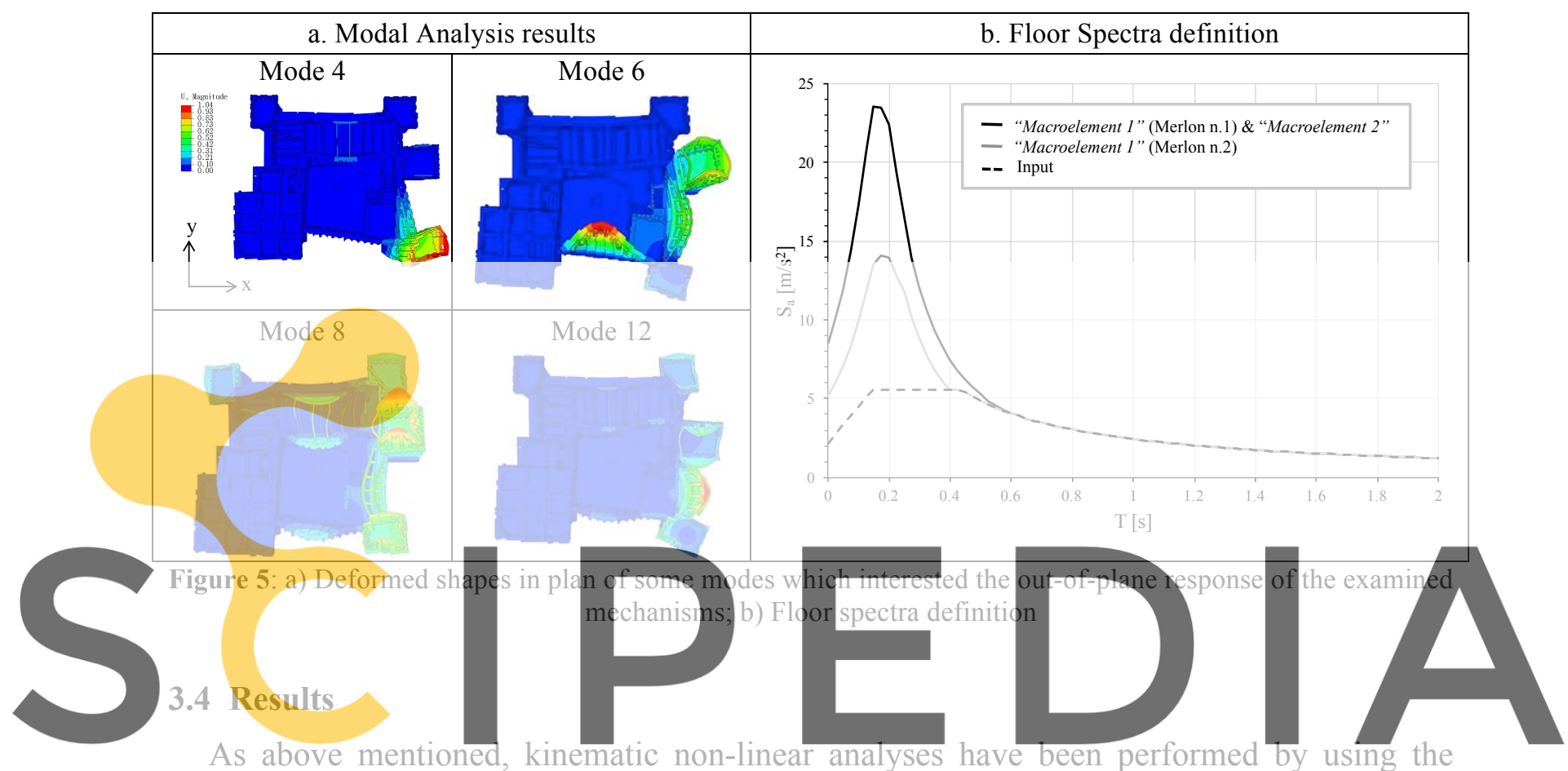

As above mentioned, kinematic non-linear analyses have been performed by using the

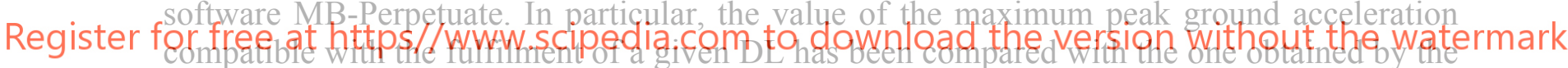
design spectrum. Table 1 illustrates the results obtained in terms of: peak ground acceleration corresponding to the fulfilment of the damage level DL2 $\left(a_{\mathrm{g}}{ }^{\text {SLD }}\right)$ and DL4 $\left(\mathrm{a}_{\mathrm{g}}{ }^{\text {SLV }}\right)$; peak ground acceleration of San Felice sul Panaro for the same DLs $\left(a_{\mathrm{g}}{ }^{\text {ite, }, S L D} ; a_{\mathrm{g}}{ }^{\text {site,SLV }}\right.$ ); corresponding safety factors $\alpha_{\mathrm{SLD}}=\mathrm{a}_{\mathrm{g}}{ }^{\mathrm{SLD}} / \mathrm{a}_{\mathrm{g}}{ }^{\text {ite,SLD }}$ and $\alpha_{\mathrm{SLV}}=\mathrm{a}_{\mathrm{g}}{ }^{\mathrm{SLV}} / \mathrm{a}_{\mathrm{g}}{ }^{\text {site,SLV }}$. Safety factors lower than 1 indicate that the seismic verification is not satisfied.

Table 1: Results for the examined mechanisms

\begin{tabular}{llllllll}
\hline & $\begin{array}{c}\mathrm{a}_{\mathrm{g}}^{\mathrm{SLD}} \\
{\left[\mathrm{m} / \mathrm{s}^{2}\right]}\end{array}$ & $\begin{array}{c}\mathrm{a}_{\mathrm{g}}^{\mathrm{SLV}} \\
{\left[\mathrm{m} / \mathrm{s}^{2}\right]}\end{array}$ & $\begin{array}{c}\mathrm{a}_{\mathrm{g}}{ }^{\text {site,SLD }} \\
{\left[\mathrm{m} / \mathrm{s}^{2}\right]}\end{array}$ & $\begin{array}{c}\mathrm{a}_{\mathrm{g}} \text { site,SLV } \\
{\left[\mathrm{m} / \mathrm{s}^{2}\right]}\end{array}$ & $\alpha_{\mathrm{SLD}}$ & $\alpha_{\mathrm{SLV}}$ \\
\hline "Macrolement 1" (merlon $\mathrm{n} 1)$ & 0.435 & 2.781 & 0.75 & 2.159 & 0.58 & 1.288 \\
\hline "Macroelement 2" & 0.330 & 2.736 & & 0.44 & 1.267 \\
\hline
\end{tabular}

In particular, the table shows only the results of the mechanisms named "Macroelement 1 " - merlon n.1 and "Macroelement 2", which are the ones turned out to be the most vulnerable 
with respect to the SLV LS. As one can see, while the verifications are satisfied with respect to the SLV, they are not satisfied with respect to the SLD, highlighting the vulnerability concerning the mechanisms activation.

\section{PROPOSAL OF POSSIBLE STRENGTHENING INTERVENTIONS}

\subsection{Intervention description}

The results presented in Table 1 highlight the necessity to define a strengthening intervention for the North walkway. Two different proposals have been elaborated:

a) A more traditional intervention with two vertical tie-rods $(\Phi 10$, S275 steel and prestress force equal to $10 \mathrm{kN}$ );

b) A more innovative one realized with the insertion of the two vertical tie-rods coupled in series to a device formed by springs and fixed at the top of each merlon (Figure 6). This device aims to protect the tie-rods, in order to avoid its premature plasticization. In particular, it has been designed in order to bear a maximum load equal to the tie-rods yielding force and with stiffness equal to $1.18 \cdot 10^{6} \mathrm{~N} / \mathrm{m}$. The use of an elastic device in the tie-rods has been recently proposed by [14], but in this paper the Authors have specifically proposed its application to vertical tie-rods.
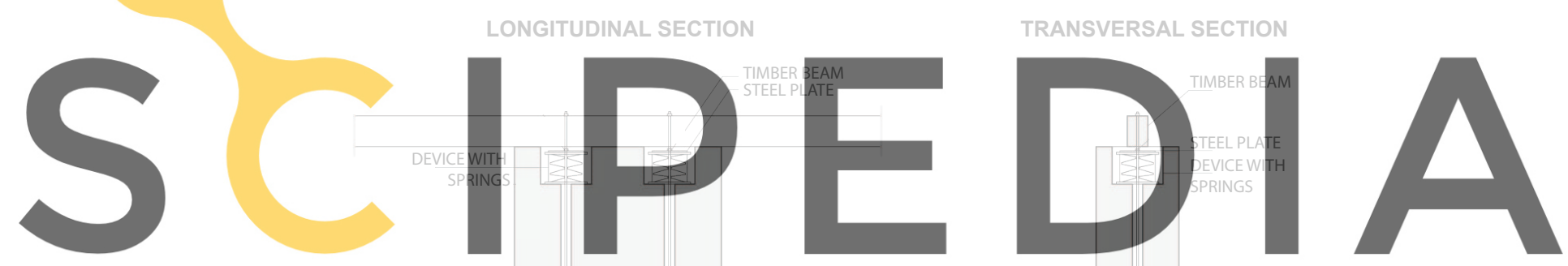

Ф10TIE-ROD
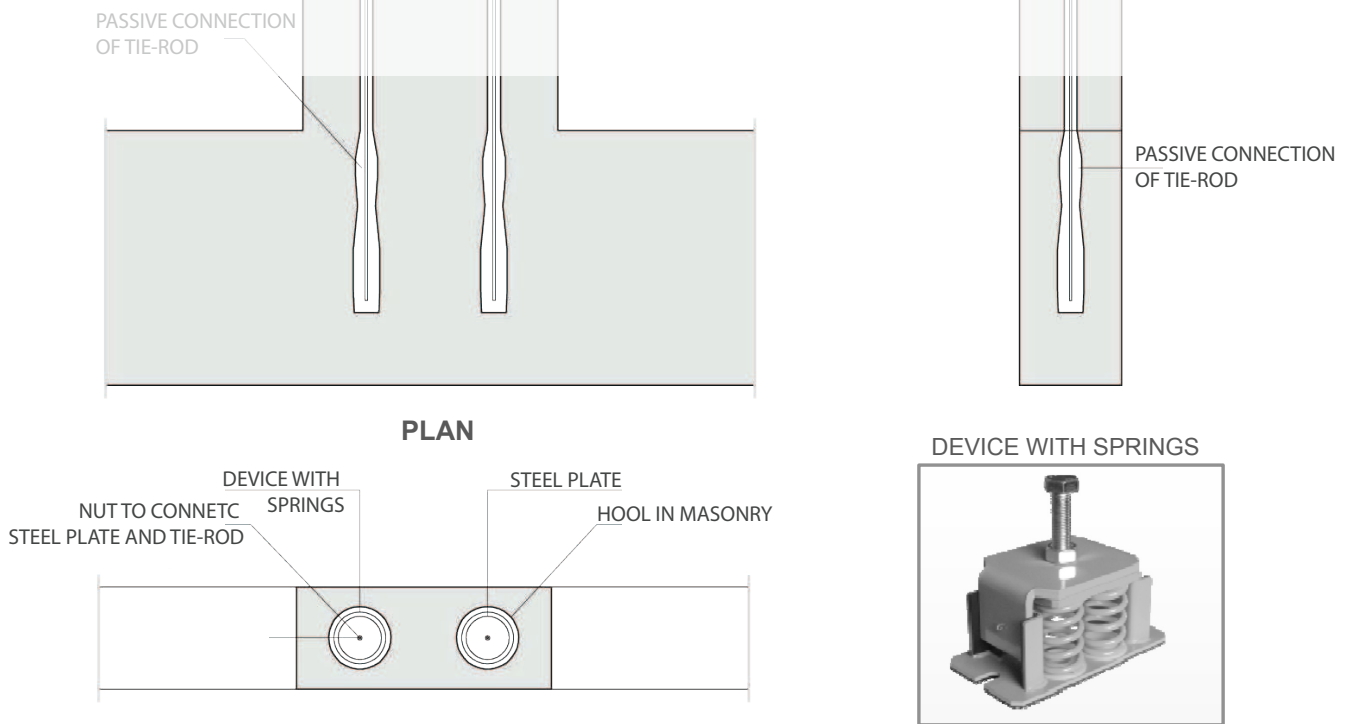

Figure 6: Sketch of the strengthening intervention provided for the merlons 
Furthermore, a proper connection between roof and battlements has to be guaranteed. In fact, the post-earthquake damage clearly showed that, sometimes, despite the high damage occurred in some merlons, they did not collapse thanks to the restraint action of the roof. The connection with the roof can be realized by means of the vertical tie-rods that strengthen the merlons: in this way, merlons and roof creates an actual "rocking frame". According to this solution, the longitudinal timber beam at the top of each merlon has to be linked to the tierods, which are longer than the merlons height and cross the timber beam. Internally, a small break has to be guaranteed in order to periodically restore the pre-stress in the bars. Finally, since the modal shapes in this area highlighted a quite pronounced flexural behaviour of the whole walkway, a double timber boarding at the roof level could be inserted, with the aim to increase the flexural stiffness of the entire walkway.

\subsection{Seismic assessment in the proposed design states}

In order to quantify the effectiveness of the two alternative possible interventions, the return periods $\left(T_{R}\right)$ inducing the Damage Limit State (SLD) and Safeguard Life Limit State (SLV) have been computed. In the analyses, the two mechanisms already presented in Table 1 have been considered. In particular, tie-rods were modelled, according to the principles of the nonlinear (incremental) kinematic analysis, as equivalent external forces, whose value is function of: initial force in the tie-rod, tie-rod's area, tie-rod's stiffness, tie-rod's yielding stress, ultimate strain. It has to be pointed out that, for the strengthening intervention b), the

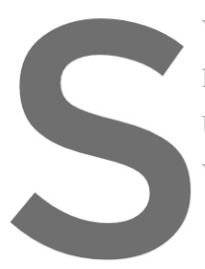
vertical tie-rods couplect rod with an equivalent underlined that the SL
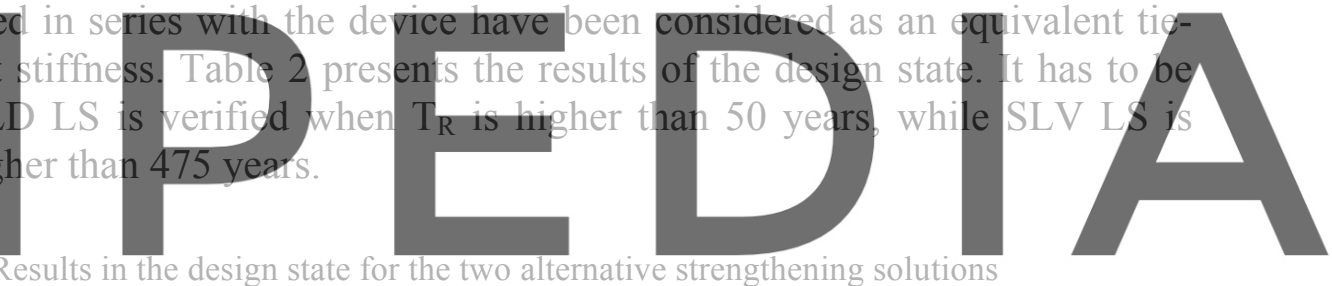

Table 2: Results in the design state for the two alternative strengthening solutions

Register for free at https//www.scipedia.com to download the version without the watermark State SLV - DL4 SSLV

\begin{tabular}{lllll}
\hline \multirow{2}{*}{$\begin{array}{l}\text { Macroelement 1" } \\
\text { (merlon } \mathrm{n} 1 \text { ) }\end{array}$} & Actual state & $\mathrm{T}_{\mathrm{R}}<30$ years & $\mathrm{T}_{\mathrm{R}}=743$ years & 1.29 \\
\cline { 2 - 5 } & Design state - sol. $\mathrm{a})$ & $\mathrm{T}_{\mathrm{R}}=127$ years & $\mathrm{T}_{\mathrm{R}}>2475$ years & 3.44 \\
\cline { 2 - 5 } "Macroelement 2" & Design state - sol. $\mathrm{b})$ & $\mathrm{T}_{\mathrm{R}}=113$ years & $\mathrm{T}_{\mathrm{R}}>2475$ years & 4.19 \\
\hline & Actual state & $\mathrm{T}_{\mathrm{R}}<30$ years & $\mathrm{T}_{\mathrm{R}}=519$ years & 1.27 \\
\cline { 2 - 5 } & Design state - sol. a) & $\mathrm{T}_{\mathrm{R}}=204$ years & $\mathrm{T}_{\mathrm{R}}>2475$ years & 2.77 \\
\cline { 2 - 5 } & Design state - sol. $\mathrm{b})$ & $\mathrm{T}_{\mathrm{R}}=175$ years & $\mathrm{T}_{\mathrm{R}}>2475$ years & 5.03 \\
\hline
\end{tabular}

As one can see from Table 2, with both the strengthening interventions, both the LSs are satisfied. However, the best choice seems to be the solution b), since it allows protecting the tie-rod from a premature plasticization, as one can see from the comparison in terms of capacity curves (Figure 7). In fact, while with the traditional solution (a) the DL4 occurs when the tie-rod is already collapsed, with the more innovative one (b) this DL occurs when the tierod is just yielded.

Furthermore, the higher effectiveness of the solution b) is also highlighted by computing the value of the peak ground acceleration corresponding to the beginning of the yielding 
(Table 3), from which one can see that with the SLV response spectrum (characterized by a PGA equal to $2.16 \mathrm{~m} / \mathrm{s}^{2}$ ), the traditional tie-rod (and not the tie-rod coupled in series to the device with springs) would be already yielded imposing its replacing after the potential occurrence of such a seismic event.

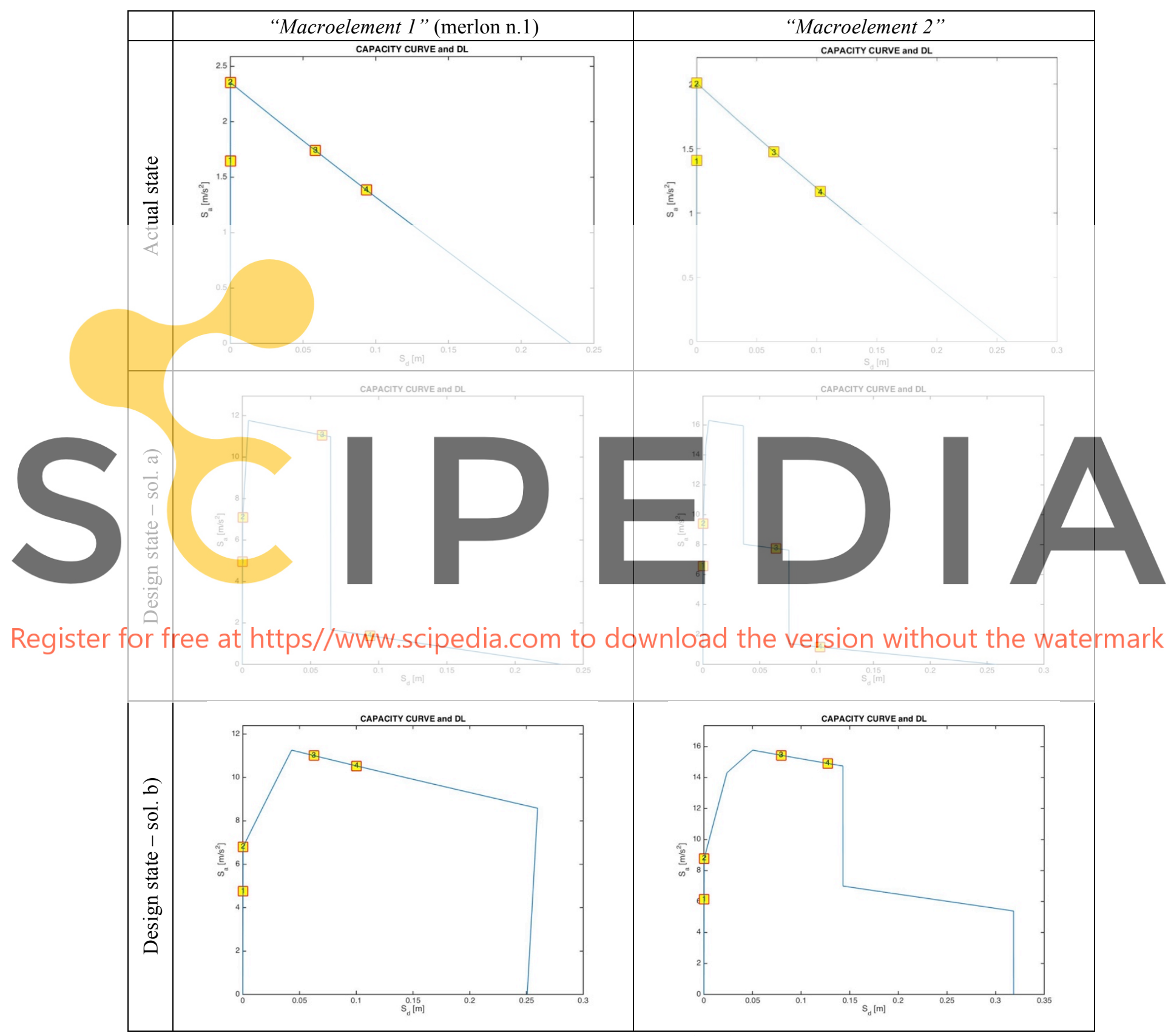

Figure 7: Capacity curves in the actual and design states 
Table 3: Values of PGA corresponding to the yielding in the two solutions of intervention

\begin{tabular}{|c|c|c|}
\hline & Sol. a) & Sol. b) \\
\hline $\mathrm{PGA}_{\text {vielding }}\left[\mathrm{m} / \mathrm{s}^{2}\right]$ & 1.75 & 5.26 \\
\hline $\mathrm{PGA}_{\mathrm{SLV}}\left[\mathrm{m} / \mathrm{s}^{2}\right]$ & & \\
\hline
\end{tabular}

\section{FINAL REMARKS}

The paper pointed out that a reliable seismic assessment of atop single-block rocking elements (that are the merlons in the examined case) needs the proper evaluation of the filtering effect provided by the main structure. The analyses of the merlons n.1 and n.2 highlighted that it is important not only to properly quantify the seismic amplification, but also its variation depending on the mechanism position as a consequence of the modal shapes of the main structure.

The results obtained were coherent with the observed damage after the Emilian earthquake (2012), demonstrating in this way the reliability of the assumed model and the analytical expressions adopted for the computation of the seismic input.

Then, the different strengthening intervention strategies discussed in the paper clearly pointed out that it is important not only to design in terms of strength (in order to prevent the mechanism's activation), but also in terms of stiffness and ductility of the inserted tie-rod, in order to protect it from a premature plasticization and then avoid its replacing in the postearthquake phase. This strategy is compatible with the conservation needs and the criteria of easy repairability that are concepts always more frequently highlighted by the recent Italian earthquakes, also in terms of repercussions on the economic loss.

Finally, the two different presented hypotheses on the possible strengthening interventions allowed outlining the most effective solution, able to minimize the impact on the construction and guarantee its preservation.

Acknowledgements. The activities have been originally developed in the framework of the research agreement for the seismic assessment of the San Felice sul Panaro Fortress after the Emilian earthquake (2012), financed in the 2016 by the municipality of San Felice sul Panaro. Moreover, the research is still ongoing within the national research project ReLUIS 20192021 (WP5 - Task 5.3) founded by the Italian Civil Protection Agency.

\section{REFERENCES}

[1] Cattari, S., Degli Abbati, S., Ferretti, D., Lagomarsino, S., Ottonelli, D., Tralli, A. Damage assessment of fortresses after the 2012 Emilia. Bulletin of Earthquake Engineering (2014) 12(5):2333-2365.

[2] Coïsson, E., Ferretti, D., Lenticchia, E. Analysis of damage mechanisms suffered by Italian fortified buildings hit by earthquakes in the last 40 years. Bulletin of Earthquake Engineering (2017) 15(12):5139-5166.

[3] Degli Abbati, S., D’Altri, A.M., Ottonelli, D., Castellazzi, G., Cattari, S., de Miranda, S., Lagomarsino, S. Seismic assessment of interacting structural units in complex historic 
masonry constructions by nonlinear static analyses. Computers and Structures (2019) 213:51-71.

[4] Orlando, A. Estense fortress at San Felice sul Panaro: modelling and seismic assessment. Master thesis (2014), University of Genova.

[5] Ferrari, L., Goldoni, G. Behind the sign. Inside and outside the San Felice sul Panaro fortress restoration work. Master thesis (2014), University of Parma.

[6] Lagomarsino, S., Ottonelli, D. A Macro-Block program for the seismic assessment (MBPERPETUATE). PERPETUATE - EC-FP7 project (2012), Deliverable D29, www.perpetuate.eu.

[7] Lagomarsino, S. Seismic assessment of rocking masonry structures. Bulletin of Earthquake Engineering (2015) 13(1):97-128.

[8] Degli Abbati, S., Lagomarsino, S. Out-of-plane static and dynamic response of masonry panels. Engineering Structures (2017) 150:803-820.

[9] Degli Abbati, S., Cattari, S., Lagomarsino, S. Theoretically-based and practice-oriented formulations for the floor spectra evaluation. Earthquake and Structures (2018) 15(5):565-581.

[10] CEN (2004), Eurocode 8: Design of Structures for Earthquake Resistance Part 1: General Rules, Seismic Actions and Rules for Buildings, European Code EN 1998 1, European Committee for Standardization, Brussels.

[11] Castellazzi, G., D’Altri, A.M., Bitelli, G., Selvaggi, I., Lambertini, A. From laser scanning to finite element analysis of complex buildings by using a semi-automatic procedure. Sensors (2015) 15(8): 18360-80.

[12] Castellazzi, G., D’Altri, A.M., de Miranda, S., Ubertini, F. An innovative numerical modeling strategy for the structural analysis of historical monumental buildings. Engineering Structures (2017) 132:229-48.

[13] NTC 2018. Italian Technical Code, Decreto Ministeriale 17/1/2018. "Aggiornamento delle Norme tecniche per le costruzioni". Ministry of Infrastructures and Transportation, G.U. n.42 of 20/2/2018 (In Italian).

[14] Melatti, V., D'Ayala, D., Modolo, E. Computational validation of dissipative device for the seismic upgrade of historic buildings. Proc. of $7^{\text {th }}$ International Conference on Computational Methods in Structural Dynamics and Earthquake Engineering Compdyn (2019), 24-26 June, Crete (Greece). 